\title{
Article \\ Can Potential Defects in LPBF Be Healed from the Laser Exposure of Subsequent Layers? A Quantitative Study
}

\author{
Alexander Ulbricht ${ }^{1, *}$, Gunther Mohr ${ }^{1,2}{ }^{\text {, Simon J. Altenburg }}{ }^{1} \mathbb{D}$, Simon Oster ${ }^{1} \mathbb{D}$, Christiane Maierhofer ${ }^{1}$ \\ and Giovanni Bruno 1,3 (D)
}

1 Bundesanstalt für Materialforschung und-Prüfung (BAM, Federal Institute for Materials Research and Testing), Unter den Eichen 87, 12205 Berlin, Germany; gunther.mohr@bam.de (G.M.); Simon.Altenburg@bam.de (S.J.A.); simon.oster@bam.de (S.O.); Christiane.Maierhofer@bam.de (C.M.); Giovanni.bruno@bam.de (G.B.)

2 Institute of Machine Tools and Factory Management, Technische Universität Berlin, Straße des 17. Juni 135, 10623 Berlin, Germany

3 Institute of Physics and Astronomy, University of Potsdam, Karl-Liebknecht-Straße 24/25, 14476 Potsdam, Germany

* Correspondence: alexander.ulbricht@bam.de

check for updates

Citation: Ulbricht, A.; Mohr, G.; Altenburg, S.J.; Oster, S.; Maierhofer, C.; Bruno, G. Can Potential Defects in LPBF Be Healed from the Laser Exposure of Subsequent Layers? A Quantitative Study. Metals 2021, 11, 1012. https://doi.org/10.3390/ met11071012

Academic Editors: Tomasz Czujko and Matteo Benedetti

Received: 11 May 2021

Accepted: 17 June 2021

Published: 24 June 2021

Publisher's Note: MDPI stays neutral with regard to jurisdictional claims in published maps and institutional affiliations.

Copyright: (c) 2021 by the authors. Licensee MDPI, Basel, Switzerland. This article is an open access article distributed under the terms and conditions of the Creative Commons Attribution (CC BY) license (https:// creativecommons.org/licenses/by/ $4.0 /)$.

\begin{abstract}
Additive manufacturing (AM) of metals and in particular laser powder bed fusion (LPBF) enables a degree of freedom in design unparalleled by conventional subtractive methods. To ensure that the designed precision is matched by the produced LPBF parts, a full understanding of the interaction between the laser and the feedstock powder is needed. It has been shown that the laser also melts subjacent layers of material underneath. This effect plays a key role when designing small cavities or overhanging structures, because, in these cases, the material underneath is feed-stock powder. In this study, we quantify the extension of the melt pool during laser illumination of powder layers and the defect spatial distribution in a cylindrical specimen. During the LPBF process, several layers were intentionally not exposed to the laser beam at various locations, while the build process was monitored by thermography and optical tomography. The cylinder was finally scanned by X-ray computed tomography (XCT). To correlate the positions of the unmolten layers in the part, a staircase was manufactured around the cylinder for easier registration. The results show that healing among layers occurs if a scan strategy is applied, where the orientation of the hatches is changed for each subsequent layer. They also show that small pores and surface roughness of solidified material below a thick layer of unmolten material $(>200 \mu \mathrm{m})$ serve as seeding points for larger voids. The orientation of the first two layers fully exposed after a thick layer of unmolten powder shapes the orientation of these voids, created by a lack of fusion.
\end{abstract}

Keywords: selective laser melting (SLM); additive manufacturing (AM); process monitoring; infrared thermography; optical tomography; X-ray computed tomography (XCT); healing; in situ monitoring

\section{Introduction}

Additive manufacturing (AM) of metals has evolved from a method for rapid prototyping to a production process applied in many industries including automotive, aerospace, and railway [1]. Among the AM methods established for metals, laser powder bed fusion (LPBF) is the most widely used, as it can produce net-shaped parts, which do not necessarily need additional surface treatments. To design LPBF parts, it is necessary to understand how the laser interacts with the layers of molten and unmolten powder. Previous studies have shown that the laser also melts, in addition to the current layer of powder, subjacent layers [2,3]. This effect is actually needed for a strong bonding between the layers and to prevent lack-of-fusion (LoF) defects $[4,5]$. If the volumetric energy density is high enough, the melt pool may not only re-melt solidified material, but also entrap keyhole pores into the bulk material up to several hundred of $\mu \mathrm{m}$ below the currently illuminated surface [6]. 
Therefore, the melting process of subjacent layers needs to be kept in mind when designing parts with cavities or overhanging structures [7]. To address this issue, LPBF machine manufacturers provide specialized downskin process parameters [8,9]. Many studies have been focussed on the determination of the part quality from in-situ monitored process signals of the build process $[6,10-13]$. In situ monitoring techniques based on thermographic cameras usually aim at the quantification of thermal inhomogeneities (within the current built surface or a stack of surfaces) to predict the formation of voids in the final part. The main drawback of thermographic techniques is the inability to observe the effect of the melt pool in the underlying, previously exposed layers.

To predict the existence of defects in the final part (i.e., voids whose forms, positions, and sizes might be a threat to the service life of the component) from in situ surface temperature data, it is necessary to understand the influence of the melt pool penetration depth on unmolten powder. Thus, several studies reported results from simulations $[14,15]$ and experiments $[16,17]$ on the interaction between melt pool and powder.

Based on these results, this study aimed to evaluate how the laser exposure of superjacent layers affects void formation in previously non-exposed areas of different heights in an LPBF specimen. A particular question is, if and how the laser exposure of superjacent layers can heal or close voids by successive melting of material in these areas.

In an LPBF specimen made of AISI 316L austenitic stainless-steel, a few consecutive layers were not directly exposed to the laser at nine different locations along the height of a cylindrical specimen. A scan strategy that rotates the orientation of a stripe scan pattern for each layer was applied to correlate the shape of detected voids to the scan pattern of distinct layers.

The build process was in situ monitored using thermographic cameras and optical tomography (the same LPBF machine and a similar optical setup as in [6]). The results from optical tomography (OT) enabled the extraction of the deployed orientations of hatches in each layer. OT was also used to study the integral intensity of the emitted thermal radiation of each built layer.

To analyse the final component, X-ray computed tomography (XCT) was used. This widely accepted non-destructive 3D measuring method enables quantitative characterisation of internal structures and volumetric irregularities; it also allows the evaluation of the geometrical precision of the built part compared with its planned design [6,18].

Additionally, we also used XCT data to capture the influence of the shape of internal surfaces and roughness on the formation of voids.

\section{Materials and Methods}

\subsection{Material and Machine}

Gas atomized powder of AISI 316L austenitic stainless steel was used as feedstock material on a commercial LPBF system SLM280 HL (SLM Solutions Group AG, Lübeck, Germany). The machine was equipped with a single $400 \mathrm{~W}$ continuous wave ytterbium fiber laser. In the focal position, a spot size of $80 \mu \mathrm{m}$ at an emitted wavelength of 1070 $\mathrm{nm}$ was used [6]. The standard process parameters for 316L provided by the machine's manufacturer were applied for the build process: laser power $\mathrm{P}=275 \mathrm{~W}$, scan velocity vs. $=700 \mathrm{~mm} / \mathrm{s}$, layer thickness $\mathrm{t}=50 \mu \mathrm{m}$, and hatching distance $\mathrm{h}=120 \mu \mathrm{m}$. Sky writing was used during the build job to prevent changes in the volumetric energy density at the end of scan tracks, where the laser guiding system needed to be aligned to the orientation of the next scan track. The powder specifications given by its supplier are listed in Table 1. Argon was used as shielding gas during the build job with a resulting oxygen content of less than $0.1 \%$.

Table 1. Powder characteristics (AISI 316L).

\begin{tabular}{ccccc}
\hline Apparent Density & Mean Diameter & $\mathbf{D}_{\mathbf{1 0}}$ & $\mathbf{D}_{\mathbf{5 0}}$ & $\mathbf{D}_{\mathbf{9 0}}$ \\
\hline $4.58 \mathrm{~g} / \mathrm{cm}^{3}$ & $35 \mu \mathrm{m}$ & $18 \mu \mathrm{m}$ & $31 \mu \mathrm{m}$ & $56 \mu \mathrm{m}$ \\
\hline
\end{tabular}




\subsection{Specimen Design}

A cylindrical specimen with a height of $12 \mathrm{~mm}$ and a diameter of $7 \mathrm{~mm}$ was designed. This resulted in a total of 240 layers based on a layer thickness of $50 \mu \mathrm{m}$. At nine specific heights, one quarter of the cylinder's circular surface was not exposed by the laser (see Table 2). To prevent heat accumulation during the build job, owing to possible voids in the non-exposed quarters, the quarters were distributed clockwise over the four quadrants of the cylinder and the build height. A $67^{\circ}$ rotation of a meandering stripe scan strategy for each layer in the bulk was applied to minimize porosity [19]. A border scan and a fill contour scan were additionally applied to ensure smooth surfaces and precise part dimensions. In the layers of the non-exposed quarters, the contour scans followed the actual three-quarter shape of the exposed section. Hence, potentially unmolten powder particles could be removed through these gaps in the surface. An ultrasonic bath of the specimen was used to remove as much unmolten powder as possible from the non-exposed quarters of the manufactured specimen.

Table 2. Overview of the position and characteristics of the non-exposed quarters. The height to be exposed included the height of the non-exposed quarter plus the height of the first fully exposed layer above $(50 \mu \mathrm{m})$.

\begin{tabular}{cccccc}
\hline $\begin{array}{c}\text { Quarter's } \\
\text { Number }\end{array}$ & $\begin{array}{c}\text { Start Height from } \\
\text { Cylindrical Base }\end{array}$ & $\begin{array}{c}\text { Number of } \\
\text { Non-Exposed Layers }\end{array}$ & $\begin{array}{c}\text { Height of the } \\
\text { Non-Exposed Quarters }\end{array}$ & $\begin{array}{c}\text { Layer } \\
\text { Numbers }\end{array}$ & $\begin{array}{c}\text { Height to be } \\
\text { Exposed }\end{array}$ \\
\hline Q1 & $3 \mathrm{~mm}$ & 1 & $50 \mu \mathrm{m}$ & 61 & $100 \mu \mathrm{m}$ \\
Q2 & $4 \mathrm{~mm}$ & 2 & $100 \mu \mathrm{m}$ & $81-82$ & $150 \mu \mathrm{m}$ \\
Q3 & $5 \mathrm{~mm}$ & 3 & $150 \mu \mathrm{m}$ & $101-103$ & $200 \mu \mathrm{m}$ \\
Q4 & $6 \mathrm{~mm}$ & 4 & $200 \mu \mathrm{m}$ & $121-124$ & $250 \mu \mathrm{m}$ \\
Q5 & $7 \mathrm{~mm}$ & 5 & $250 \mu \mathrm{m}$ & $141-145$ & $300 \mu \mathrm{m}$ \\
Q6 & $8 \mathrm{~mm}$ & 6 & $300 \mu \mathrm{m}$ & $161-166$ & $350 \mu \mathrm{m}$ \\
Q7 & $9 \mathrm{~mm}$ & 7 & $350 \mu \mathrm{m}$ & $181-187$ & $400 \mu \mathrm{m}$ \\
Q8 & $10 \mathrm{~mm}$ & 8 & $400 \mu \mathrm{m}$ & $201-208$ & $450 \mu \mathrm{m}$ \\
Q9 & $11 \mathrm{~mm}$ & 9 & $450 \mu \mathrm{m}$ & $221-229$ & $500 \mu \mathrm{m}$ \\
\hline
\end{tabular}

To analyse the ability of the laser exposure of subsequent layers to fully melt subjacent layers of powder, a precise registration of the XCT results as well as of the in situ monitoring results was needed. Hence, a (helical) staircase was designed to be manufactured around the cylinder. This design was derived from Gobert et al. [20], who introduced additional staircases to enable a better registration of observable features to a distinct layer. Here, every step of the staircase represented the starting height of a non-exposed quarter of the inner cylinder. A small gap was introduced between the staircase and cylinder to enable an easy removal of the staircase and enable high resolution XCT scans. In order to improve the registration of a rotational symmetric specimen, an embossed T-shaped mark was added to the top surface (see Figure 1).
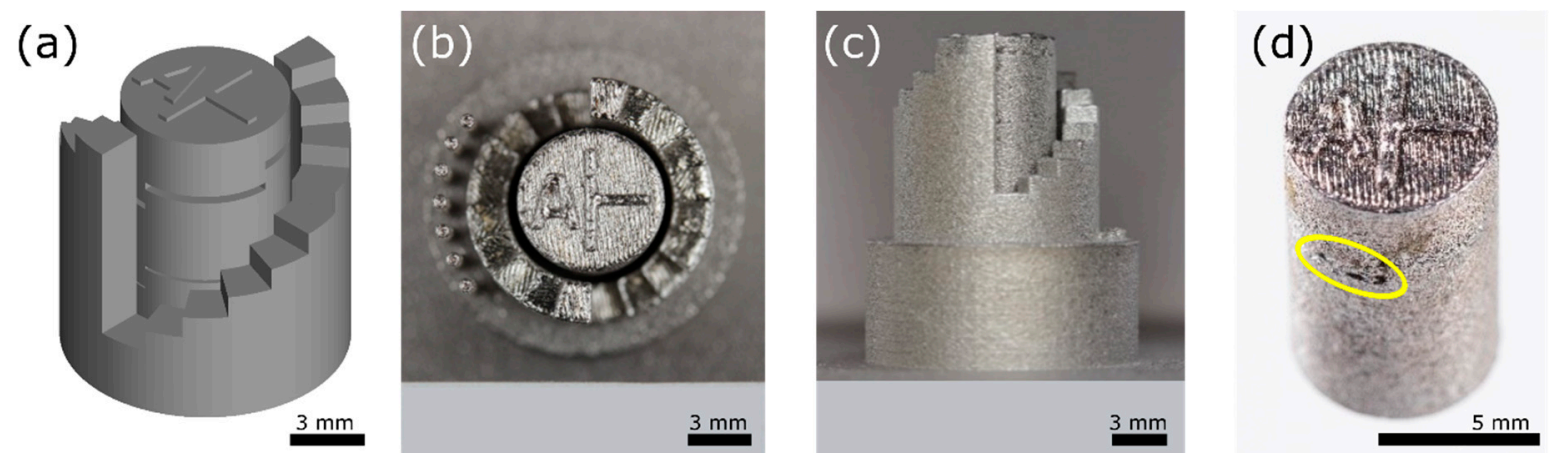

Figure 1. (a) CAD file of the specimen including the staircase; (b) Photograph of the produced specimen (top view, including the trigger pins) (c) Photograph of the produced specimen (side view) (d) Photograph of the specimen after the removal of the staircase. The yellow ellipse marks an open porosity of a non-exposed quarter. 


\subsection{Optical Tomography and Thermography}

The build process was monitored in situ by optical tomography (OT, bulb exposure of each layer exposition [21]) and thermography. In comparison with the optical setup within the LPBF machine's build chamber previously reported in [6], the external optical setup was modified. Beam splitters divided the radiation into an OT CMOS camera (M4020, Teledyne Digital Imaging Inc., Billerica, MA, USA) and a short wave infrared (SWIR) camera (Goldeye CL-033 TEC1, Allied Vision Technology GmbH, Stadtroda, Germany). The OT camera system was sensitive to light emission in the near infrared spectral range ( $880 \mathrm{~nm} \pm 25 \mathrm{~nm}$ ). A spatial resolution of $40 \mu \mathrm{m}$ per pixel was achieved, enabling visualisation of the hatching pattern with a hatching distance of $120 \mu \mathrm{m}$. The image data acquired by in situ OT show a map of intensity values that are proportional to the spectral radiosity of the part surface integrated in the spectral range of the used filter and over the whole layer illumination time. As the radiosity in a fixed spectral window strongly increases in the near infrared at the involved temperatures of molten steel, these intensity values are well suited as a measure for the maximum temperature reached at each point. However, as the time integral over the spectral radiosity is recorded, reduced cooling rates can also cause high OT intensities. Thus, data interpretation must be performed carefully. A comparison with the time resolved thermography data may help to clarify the origin of possible deviations in the OT intensity, despite the lower spatial resolution (factor of three).

\subsection{Micro Computed Tomography}

Micro computed tomography (XCT) was performed in two steps. An overview scan of the whole part was performed using the commercial CT-scanner GE v | tome | x 180/300 (GE Sensing \& Inspection Technologies GmbH, Wunstorf, Germany) at a voltage of $222 \mathrm{kV}$ and a current of $45 \mu \mathrm{A}$ applied with an aluminium pre-filter of $1.0 \mathrm{~mm}$ thickness. A reconstructed voxel size of $(10 \mu \mathrm{m})^{3}$ was achieved. After the removal of the staircase, the inner cylinder was scanned again using a custom-made industrial 3D micro CT scanner, which was equipped based on a $225 \mathrm{kV}$ micro focus X-Ray source (X-Ray WorX GmbH, Garbsen, Germany) [22]. A voltage of $210 \mathrm{kV}$ and a current of $60 \mu \mathrm{A}$ in combination with a metal pre-filter of $1 \mathrm{~mm}$ copper and $0.25 \mathrm{~mm}$ aluminium were used. A voxel size of $(5 \mu \mathrm{m})^{3}$ was achieved by combining the results from two measurements taken at two heights. The combined $(5 \mu \mathrm{m})^{3}$ data were filtered using the plugin "non-local means denoise" [23,24] in the open-source imaging software Fiji [25]. For further analysis, the higher resolution- $(5 \mu \mathrm{m})^{3}$ voxel size-data were registered onto the lower resolution$(10 \mu \mathrm{m})^{3}$ voxel size-data using the commercial software VG Studio MAX version 3.3.3 (Volume Graphics GmbH, Heidelberg, Germany). The same software was used for all XCT data analyses. The $(5 \mu \mathrm{m})^{3}$ voxel size data enabled the quantitative analysis of voids with size above $(10 \mu \mathrm{m})^{3}$. The analysis was performed in a virtual cylindrical cut-out $(\varnothing=6.87 \mathrm{~mm}, \mathrm{~L}=11 \mathrm{~mm})$ of the inner cylinder $(\varnothing=7 \mathrm{~mm}, \mathrm{~L}=11.86 \mathrm{~mm})$ to prevent surface roughness from influencing the size determination of open voids. The volumetric porosity was analysed using VG Studio MAX's built-in porosity analysis modules. A lower threshold for void detection was set to 8 voxels. To correlate the main orientation of the voids with the orientation of the stripe scan pattern, virtual lines were fitted onto the voids of virtual cuts in the VG Studio MAX software. The built-in dimensioning tool was used to calculate the angles of the LoF voids from a set $0^{\circ}$ reference line.

\section{Results}

\subsection{In Situ Monitoring}

The OT results from layer 200 (last fully exposed layer before the beginning of Q8, see Table 1) and layer 209 (first fully exposed layer after Q8) are exemplarily depicted in Figure 2. From the OT data, the rotation angle $\alpha$ of the meandering stripe pattern was extracted. Exemplarily, the rotation angles of these two layers are indicated, $\alpha_{(\text {layer 200) }}=75^{\circ}$ and $\alpha_{(\text {layer 209) }}=13^{\circ}$. The comparison of the OT data revealed lower intensities in the quarter of layer 209, which covered the unexposed quadrant I. A comparison with time 
resolved thermography results shows that the spectral radiosity in the wavelength window of the SWIR camera was reduced in this quadrant as well. Thus, the maximum temperature reached in this quadrant was indeed lower than in the other quadrants. Ghost images appeared in the OT data, caused by the optical set-up, adding some blur to the images. The resulting offset intensity error in the superposed areas is in the range of approximately $+8 \%$ related to peak intensity.

(a)

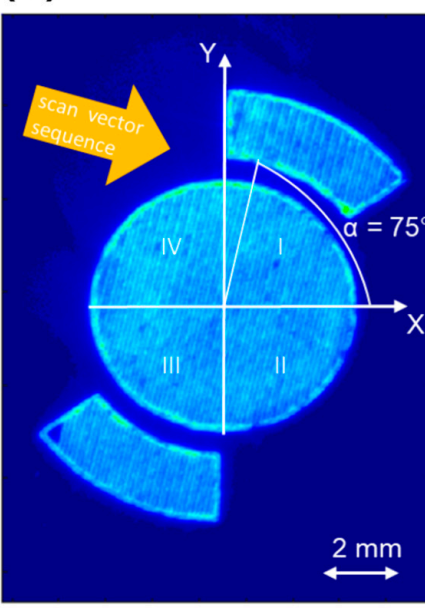

Intensity in DV

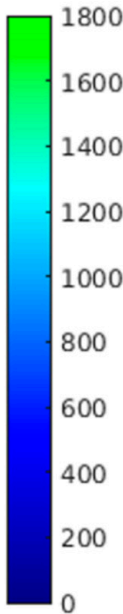

(b)

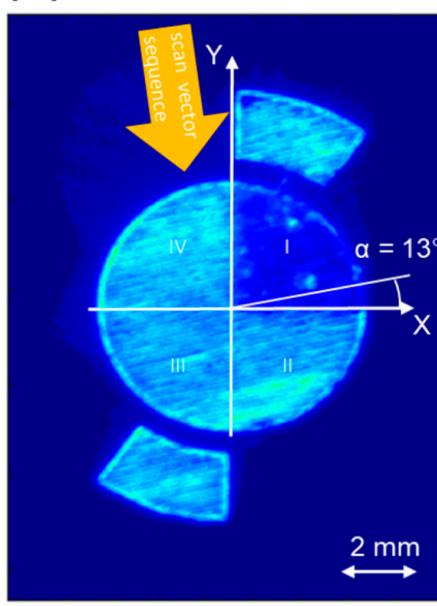

Intensity in DV

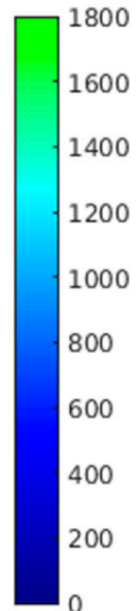

Figure 2. Optical tomography (OT) images showing the orientation of the hatches for (a) layer 200 (last complete layer below Q8) and (b) layer 209 (first complete layer above Q8).

\subsection{XCT}

The XCT results showed that, in all of the nine quarters, most of the powder was molten by the laser exposure (see Figure 3 and Table 3). Figure 3 shows the 3D rendering of the segmented voids in the whole cylindrical specimen. Figures 4 and 5 show the segmented voids in a virtual cut of the XCT data as well as the 3D rendered void segmentation. As shown in Figure 5e,f and Table 3, at a height of $450 \mu \mathrm{m}(+50 \mu \mathrm{m}$ of the superjacent fully exposed layer) of unmolten powder, a porosity of $5.56 \%$ was observed. This was surprisingly low as the unexposed volume was expected to contain many unmolten powder particles. Instead, solid material with LoF voids was observed.

(a)

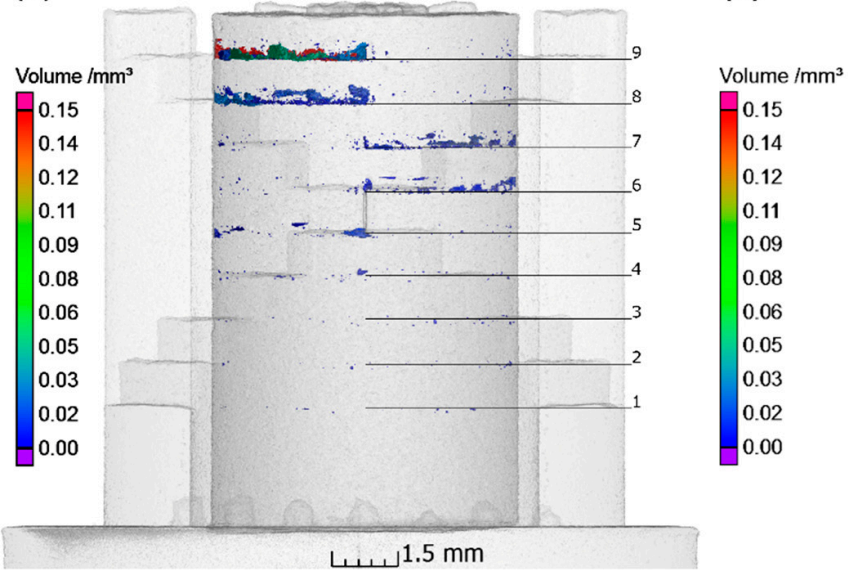

(b)

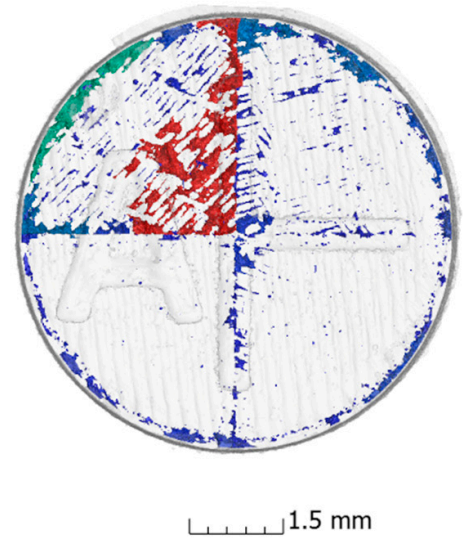

Figure 3. (a) Sideview of the combined rendering of the $(10 \mu \mathrm{m})^{3}$ data and the $(5 \mu \mathrm{m})^{3}$ data showing segmented voids in the high-resolution data; (b) top view of the rendering of the $(5 \mu \mathrm{m})^{3}$ data of the cylinder showing a projection of all segmented voids. 
Table 3. Porosity of the non-exposed quarters.

\begin{tabular}{cccccccccc}
\hline Quarter's Number & Q1 & Q2 & Q3 & Q4 & Q5 & Q6 & Q7 & Q8 & Q9 \\
\hline porosity & none & $0.05 \%$ & $0.04 \%$ & $0.08 \%$ & $0.38 \%$ & $0.78 \%$ & $0.80 \%$ & $2.23 \%$ & $5.56 \%$ \\
\hline
\end{tabular}

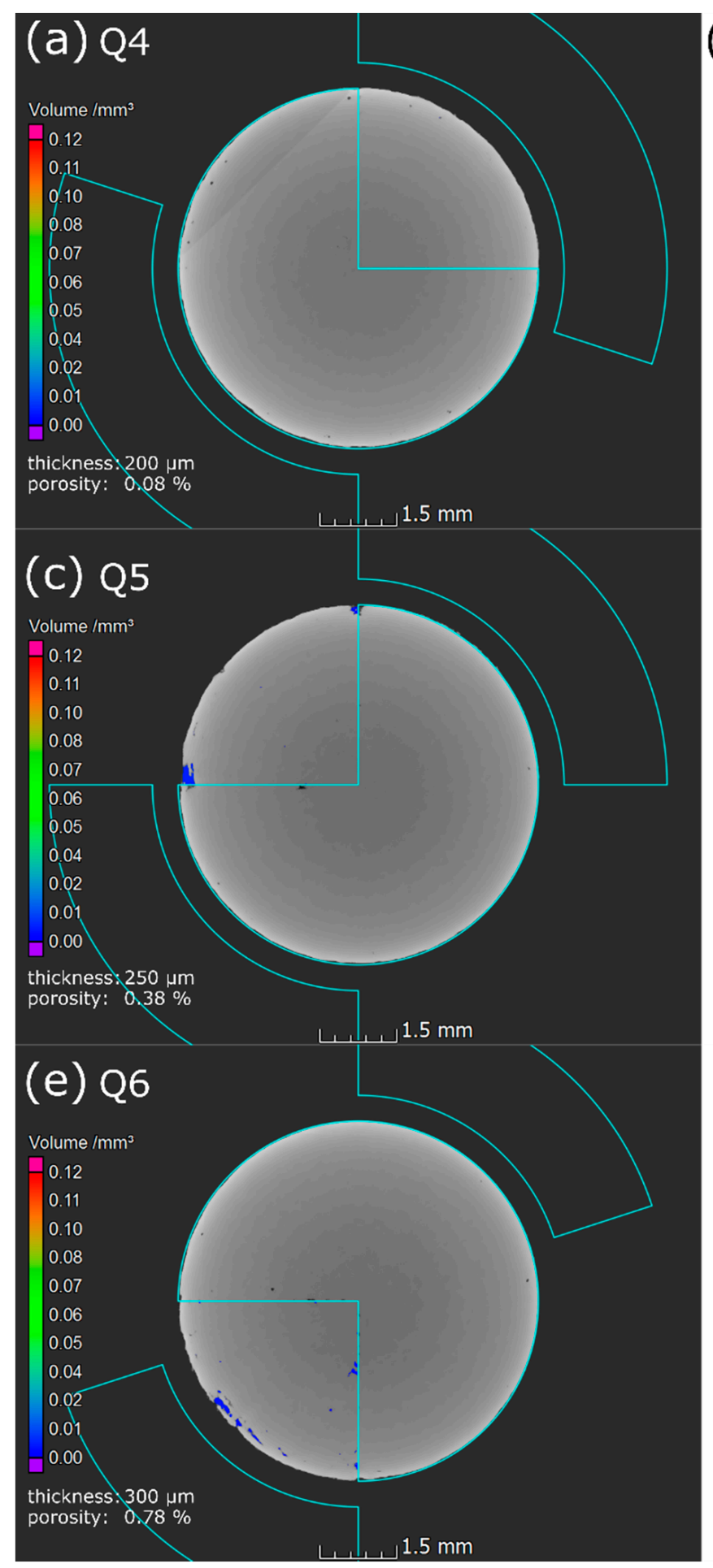

\section{(b) Q4}
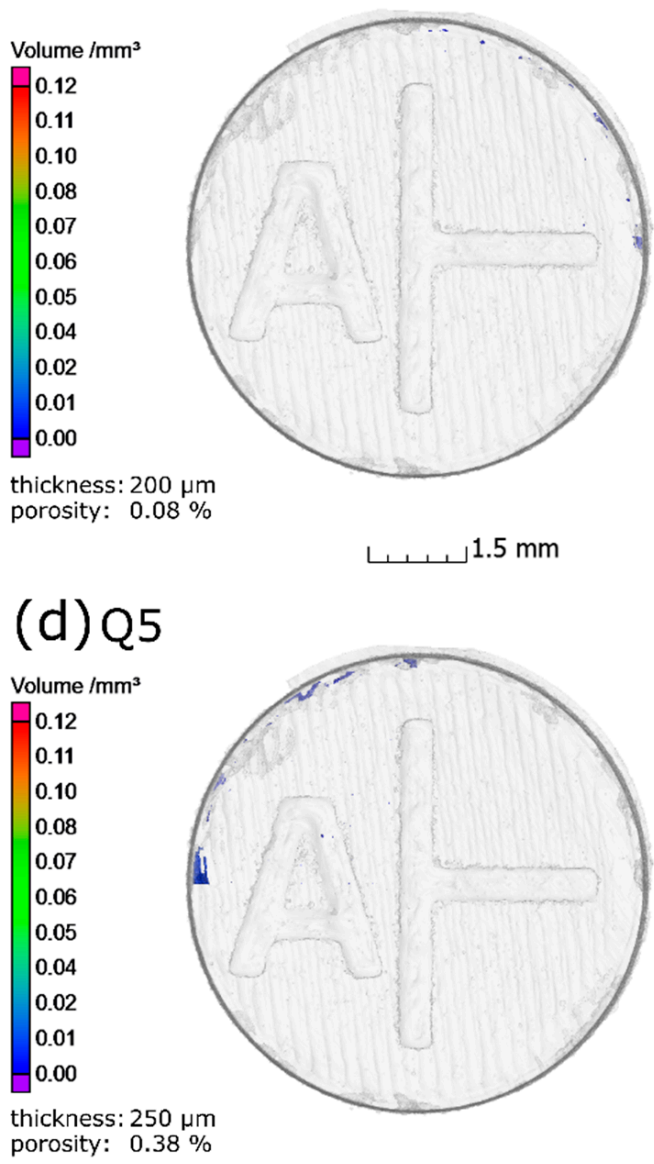
porosity: $0.38 \%$

\section{(f) Q6}

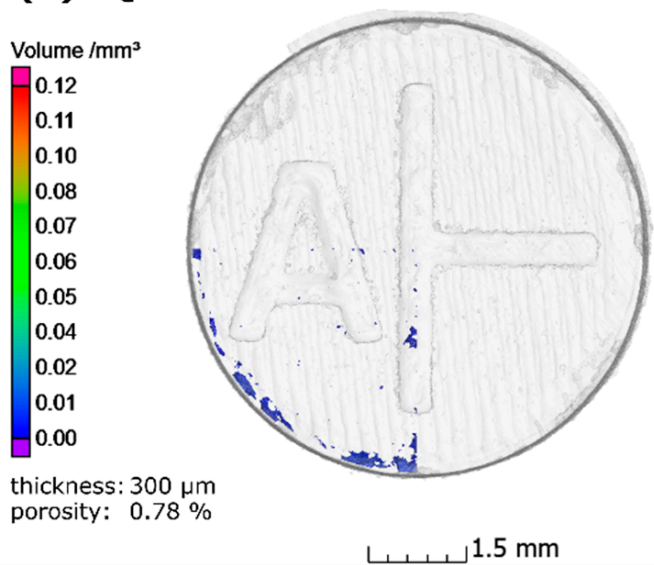

Figure 4. Void distribution at the positions of the unexposed quarters. Slice images taken at $10 \%$ of the quarter's height. (a) Q4: four layers unexposed; (b) projection of the void distribution in the unexposed layers containing Q4; (c) Q5: five layers unexposed; (d) projection of the void distribution in the unexposed layers containing Q5; (e) Q6: six layers unexposed; (f) projection of the void distribution in the unexposed layers containing Q6. 

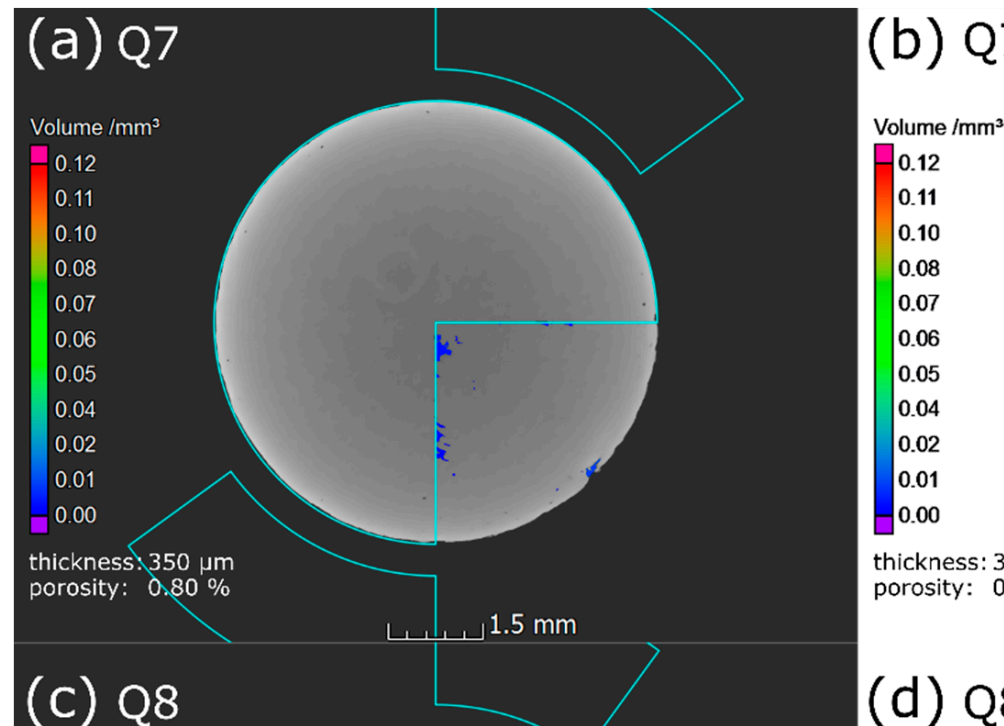

(c) $\mathrm{Q} 8$

Volume $/ \mathrm{mm}^{3}$

$-0.12$

0.11

0.10

0.08

0.07

0.06

0.05

0.04

0.02

0.01

0.00

thickness: $400 \mu \mathrm{m}$

porosity: $2.23 \%$
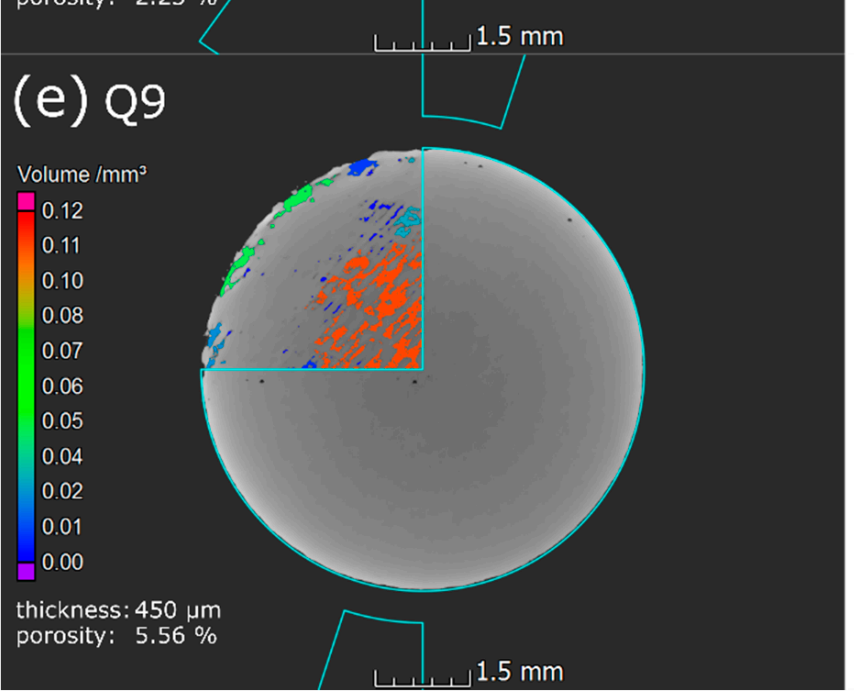

thickness: $350 \mu \mathrm{m}$ porosity: $0.80 \%$

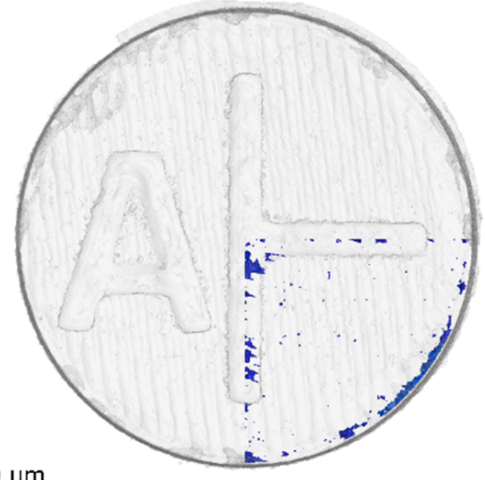

$1.5 \mathrm{~mm}$
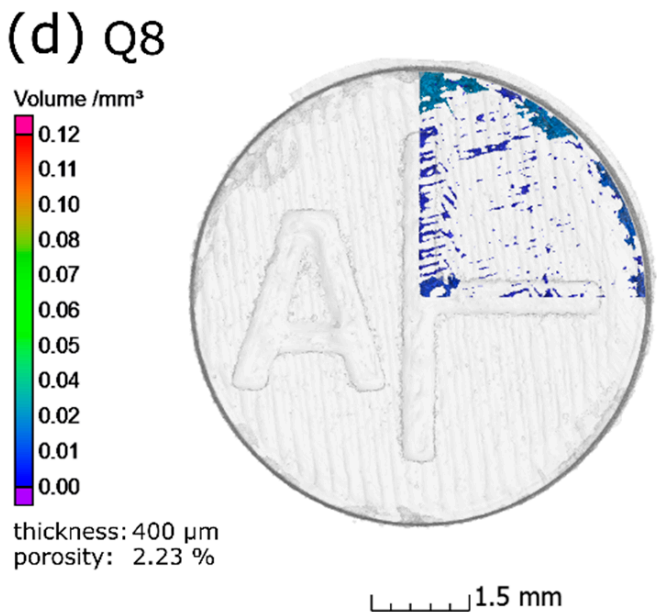

\section{(f) $Q 9$}

Volume $/ \mathrm{mm}^{3}$
0.12
0.11
0.10
0.08
0.07
0.06
0.05
0.04
0.02
0.01
0.00

thickness: $450 \mu \mathrm{m}$ porosity: $5.56 \%$

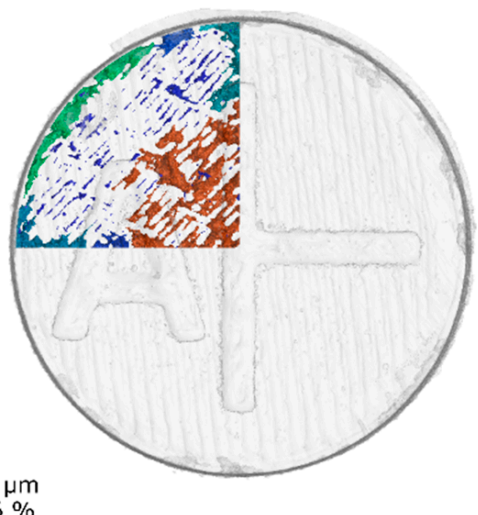

$1.5 \mathrm{~mm}$

Figure 5. Void distribution at the positions of the unexposed quarters. Slice images taken at 10\% of the quarter's height. (a) Q7: seven layers $(350 \mu \mathrm{m})$ unexposed; $(\mathbf{b})$ projection of the void distribution in the unexposed layers containing Q7; (c) Q8: eight layers unexposed; (d) projection of the void distribution in the unexposed layers containing Q8; (e) Q9: nine layers unexposed; (f) projection of the void distribution in the unexposed layers containing Q9.

At up to a thickness of $200 \mu \mathrm{m}$ of unmolten powder, almost no additional porosity due to the underexposure by the laser was observed (see Figure $4 a, b$ for $200 \mu \mathrm{m}$ of unmolten powder in Q4). In these quarters, only pores at the interface between bulk and contour scan could be detected. This observation correlates well with the results from the literature [26]. The porosity value is directly linked to the number of pores occurring inside the quarters, 
not to the explicitly unmolten layer thickness. At a non-exposed thickness of $250 \mu \mathrm{m}$ of unmolten powder (Q5), voids were detected at the positions where the outlines of the quarter intersect the perimeter of the cylinder (see Figure $4 \mathrm{c}, \mathrm{d}$ ). Voids at the quarters' inner perimeter were detected only above a non-exposed thickness of $300 \mu \mathrm{m}$ (i.e., six layers, Q6, see Figure $4 \mathrm{e}, \mathrm{f}$ and Figure $5 \mathrm{a}, \mathrm{b})$. At a thickness of 400 and $450 \mu \mathrm{m}$ of unexposed powder, areal voids were detected (see Figure $5 \mathrm{c}-\mathrm{f}, \mathrm{Q} 8$ and Q9). Figure $5 \mathrm{f}$ shows the rendered defects; they seem to correspond to hatches of the scan pattern. As the orientation of the stripe scan pattern rotated by $67^{\circ}$ with each layer, it was possible for Q6-Q9 to assign the orientation of LoF voids to distinct layers. As listed in Table 4, the main orientation of the LoF voids corresponds to the orientation of the first fully exposed layer above the quarter. For Q8 and Q9, a secondary orientation of LoF voids was also detected. Figure 7 combines the $3 \mathrm{D}$ rendering of the segmented voids with OT images of the first and second exposed layer above the quarter. The figure emphasises how the hatch orientation of these layers determined the shape of the segmented LoF voids.

Table 4. Comparison between the observed lack-of-fusion (LoF) pattern and the scan hatch orientation. OT, optical tomography.

\begin{tabular}{cccccc}
\hline $\begin{array}{c}\text { Quarter's } \\
\text { Number }\end{array}$ & $\begin{array}{c}\text { Non-Exposed } \\
\text { Height }\end{array}$ & $\begin{array}{c}\text { Primary LoF } \\
\text { Orientation } \\
\text { (XCT) }\end{array}$ & $\begin{array}{c}\text { Secondary LoF } \\
\text { Orientation } \\
\text { (XCT) }\end{array}$ & $\begin{array}{c}\text { Orientation of the } \\
\text { First Exposed } \\
\text { Layer (OT) }\end{array}$ & $\begin{array}{c}\text { Orientation of the } \\
\text { Second Exposed } \\
\text { Layer (OT) }\end{array}$ \\
\hline Q6 & $350 \mu \mathrm{m}$ & $127^{\circ}$ & - & $127^{\circ}$ & $50^{\circ}$ \\
$\mathrm{Q} 7$ & $400 \mu \mathrm{m}$ & $162^{\circ}$ & - & $160^{\circ}$ & $13^{\circ}$ \\
$\mathrm{Q} 8$ & $450 \mu \mathrm{m}$ & $14^{\circ}$ & $151^{\circ}$ & $41^{\circ}$ & $127^{\circ}$ \\
$\mathrm{Q} 9$ & $500 \mu \mathrm{m}$ & $46^{\circ}$ & $157^{\circ}$ \\
\hline
\end{tabular}

Figure 6a shows a magnified virtual cut of a large defect at the centre of Q9 obtained from the high-resolution XCT data. Figure $6 \mathrm{~b}$ revealed that voids were mainly found at the bottom of Q9 and large voids could be observed towards the perimeter of Q9. In contrast to the remaining quarters in Q9, a larger void could be observed in the centre of the quarter (see yellow highlighting in Figure 6a,b).
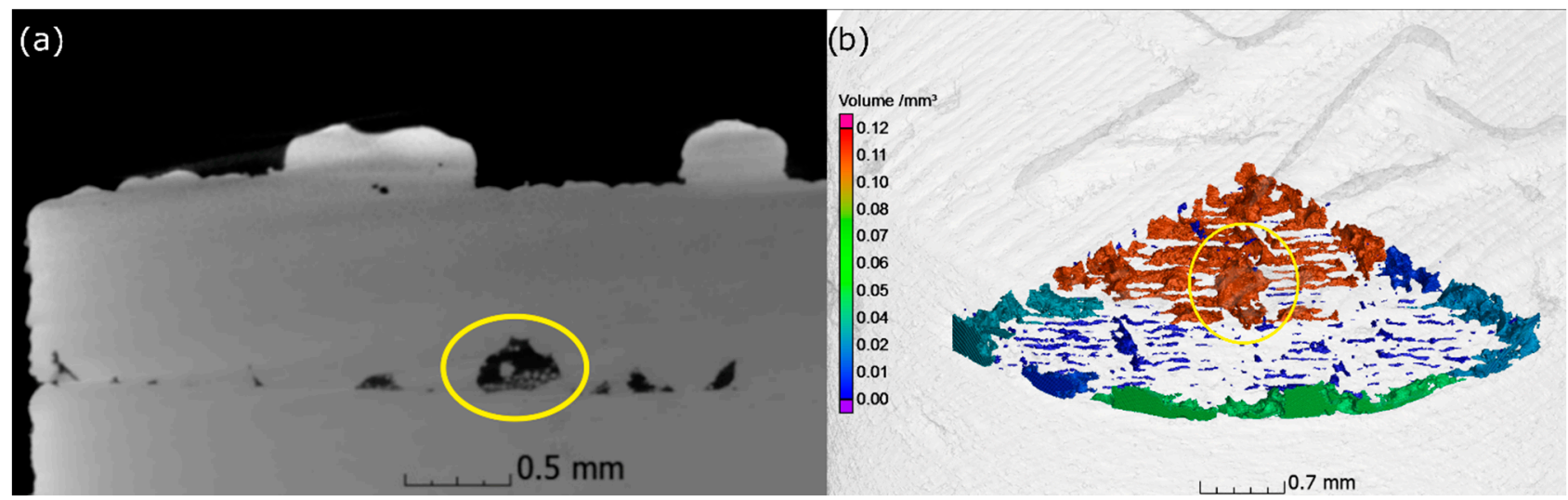

Figure 6. (a) Magnified sideview of the large defect at the centre of $Q 9$ obtained from the high-resolution $X$-ray computed tomography (XCT) data. The largest void in Q9 is highlighted; (b) 3D rendering of the voids in Q9. The yellow mark highlights the position of the largest void from (a).

\section{Discussion}

The aim of this study was to analyse the effect of healing of successive laser passes during LPBF manufacturing. We thus investigate how (and how many) unmolten layers of powder were molten to form a solid with dense connection to the underlying bulk material. Although standard machine parameters of the LPBF machine based on $50 \mu \mathrm{m}$ thick layers of powder were applied, XCT data revealed that the melt pool was deep enough to partially 
melt 10 layers of powder $(500 \mu \mathrm{m})$, thereby creating lower than expected porosity values $(5.6 \%)$. The lack of unmolten powder particles found in the non-exposed quarters illustrates the ability of the laser to transfer heat to powder layers below the surface. This result corresponds to the results from the in situ monitoring.

Figure $2 \mathrm{~b}$ reveals that the thermal radiosity in quadrant $\mathrm{I}$ of the first fully exposed layer above Q8 seems to be lower than for the regions that have solid material below. This might be surprising at a first glance, as powder can be regarded as a heat insulator [27]. Therefore, one would expect to observe a higher radiosity owing to heat accumulation above the insulating powder. To explain the observed radiosity, the ability of the laser to transfer a sufficient amount of heat to layers below the current surface should be invoked. Foroozmehr et al. [15] had simulated the optical penetration of the laser radiation into a powder bed of AISI 316L. In agreement with previous studies [14,17], they assumed, in addition to absorption, multiple reflections of the laser radiation at the surfaces of the powder particles. Therefore, the laser-powder interaction seems to be a complex combination of transmission, scattering, and absorption of the laser energy by the powder particles. The laser radiation is not only absorbed at the surface of the powder layer, but also within the layer. At Q9, the missing layer thickness was 10 times higher than the single layer thickness of $50 \mu \mathrm{m}$. This led to a higher optical penetration depth, and thus to a lower volume energy density as in the areas with the single layer thickness. Consequently, the maximum temperature and thus the radiosity detected by the OT camera of the first solidified layer is lower.

Figure 6 and Figure 9 show that the voids created by the missing illumination of the layers were mainly found at the bottom of the quarters where the melt pool could not melt powder particles [28]. As shown in Figure 7, the melt pools of the first (and, above seven unmolten layers, also the second) fully exposed layer above the non-exposed quarter shaped the detected LoF voids. At these deeper regions, the melt pool is expected to be narrower. Therefore, in such regions, melt pools from neighbouring scan tracks did not seem to overlap each other. The combination of solidification shrinkage and surface tension effects of the melt pool (e.g., Marangoni effect [29-31]), which could draw neighbouring powder particles into the melt pool, appears to have created voids between scan tracks. Further in-depth analysis of the energy limits that form LoF voids in LPBF parts has been discussed by Biffo et al. [32-34]. In Q4 to Q7, these LoF voids between scan tracks were only observed close to the perimeter of the quarter. In $Q 8$ and $Q 9$, these LoF voids were also observed in the bulk of the quarters. This indicates that, up to a depth of $350 \mu \mathrm{m}$ (below the current layer surface), neighbouring scan tracks overlap in such a way to cover the gap between them $(120 \mu \mathrm{m})$.

Figure $7 \mathrm{a}-\mathrm{d}$ shows that the orientation of the LoF voids observed in the quarters Q6-Q9 mainly corresponded to the orientation of the scan pattern of the first fully exposed layer above. This indicated that, at a depth of $350 \mu \mathrm{m}$ and below, the melt pool widths of neighbouring scan tracks do not overlap sufficiently to prevent LoF defects. Because, in Q6 and Q7, this observation was made only at positions close to the edge of the quarters, the melt pool width seemed to vary during the laser exposure. In Q8 and Q9, a secondary orientation of LoF voids was also observed. This showed that the melt pool depth of the first solidified layer was lower than the powder layer thickness, leaving some unmolten power at the bottom of Q8 and Q9. The penetration depth of the melt pool did not seem to be constant, because, up to Q8 (powder height of $400 \mu \mathrm{m}$ ), only small voids (height $<100 \mu \mathrm{m}$ ) at the bottom of the quarter were detected. In Q9 (quarter height of $450 \mu \mathrm{m}$ ), a network of large voids with a height of up to $300 \mu \mathrm{m}$ was observed (see highlighted void in Figure $6 \mathrm{~b}$ ). The lack of large voids in quarters Q1-Q5 indicates that the laser energy density was sufficient to melt several layers of powder in the non-exposed quarters. 
(a) Q6
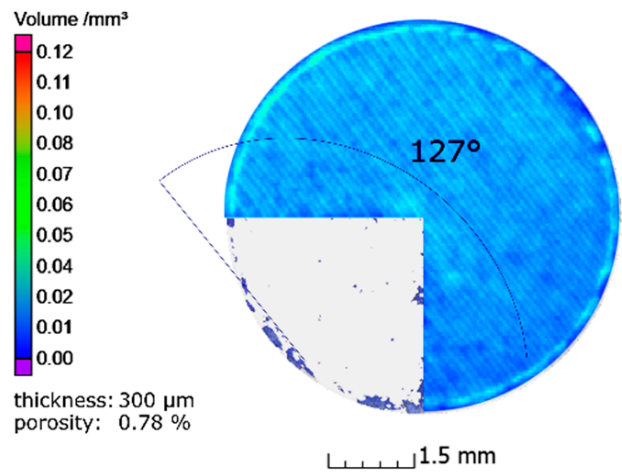

(c) Q8

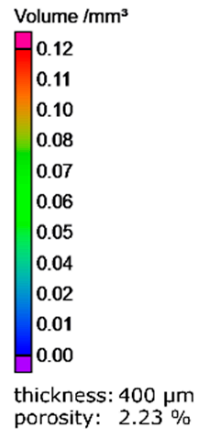

(e) Q8

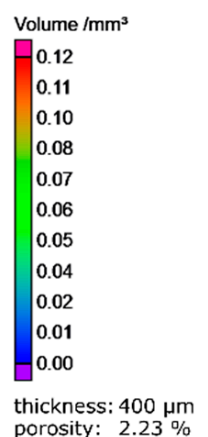
thickness: $400 \mu \mathrm{m}$
porosity: $2.23 \%$

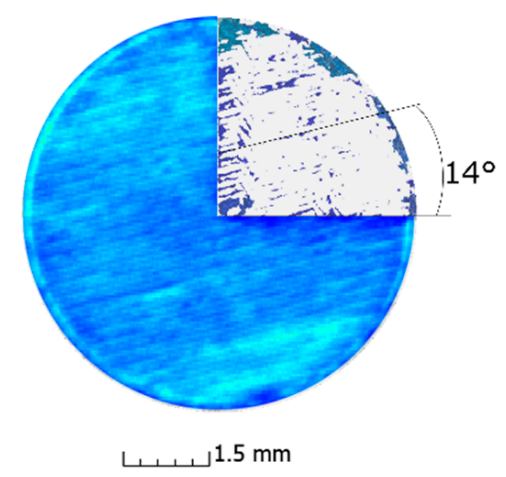

$121^{\circ}$

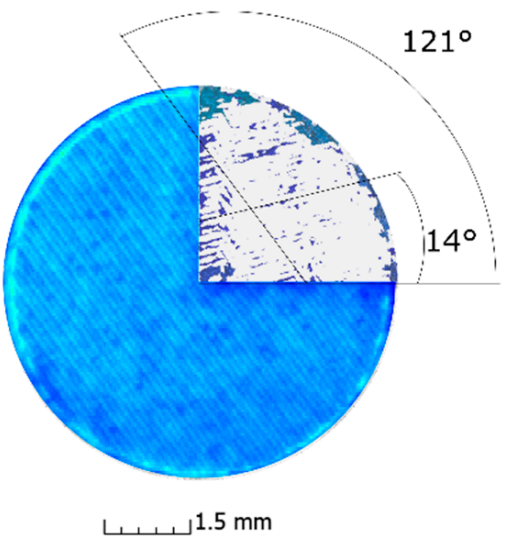

(b) Q7

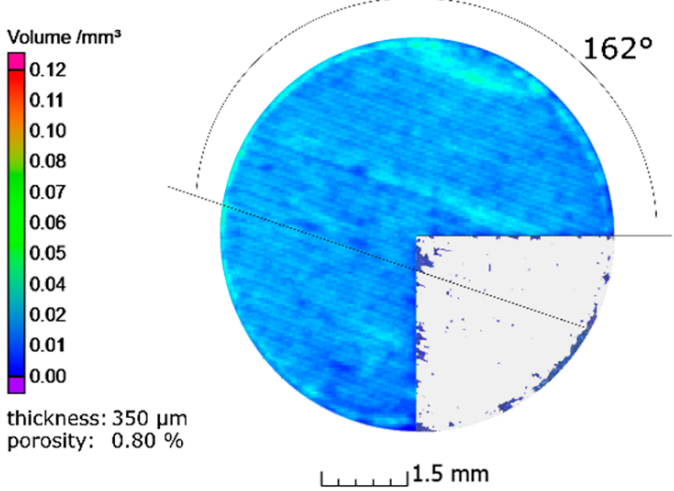

\section{(d) Q9}

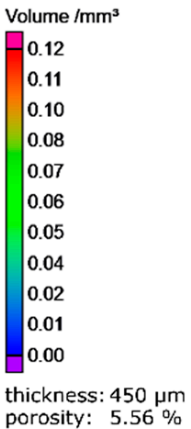

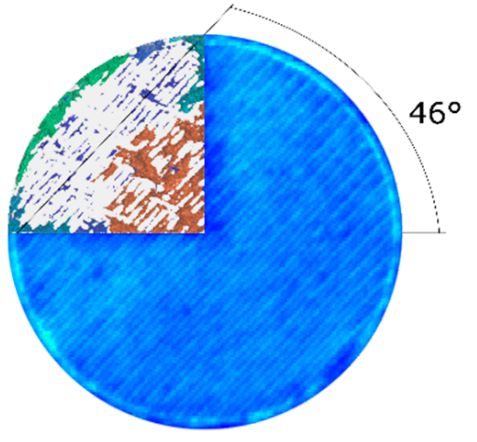

, $1.5 \mathrm{~mm}$

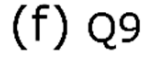

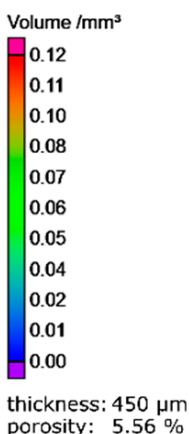

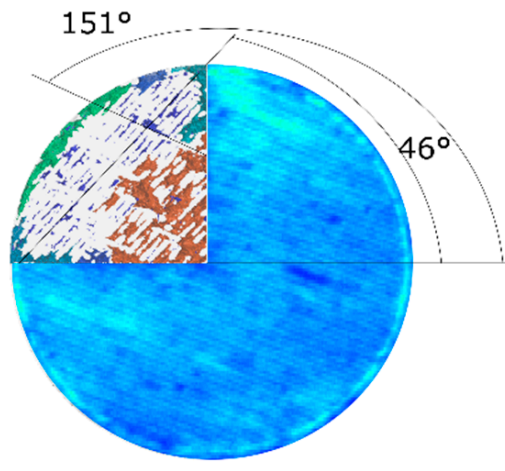

$\leftarrow,+1.5 \mathrm{~mm}$

Figure 7. Combination of optical tomography images of the first fully exposed layers above the quarters and the orientation of LoF voids, as detected by XCT. (a) Void distribution of Q6 combined with the OT of the first layer above; (b) void distribution of Q7 combined with the OT of the first layer above; (c) void distribution of Q8 combined with the OT of the first layer above; (d) void distribution of Q9 combined with the OT of the first layer above; (e) void segmentation of Q8 combined with the OT of the second layer above; (f) void distribution of Q9 combined with the OT of the second layer above.

Figure 8 shows a third orientation of LoF voids close to the bottom surface of Q8 and Q9. The combination of XCT and OT data revealed that their orientation corresponds to the orientation of layer numbers 200 (in the case of Q8) and 220 (in the case of Q9). These layers were the last fully exposed layers below the non-exposed quarters. The virtual cuts presented in Figure 8 were taken $60 \mu \mathrm{m}$ above the bottom of Q8 and $10 \mu \mathrm{m}$ below the bottom of Q9. Still, at that height, the orientation of the underlying solidified surface seemed to influence the orientation of LoF voids. It can be assumed that the surface roughness of these layers served as seeding points for the larger LoF voids in the quarters. 


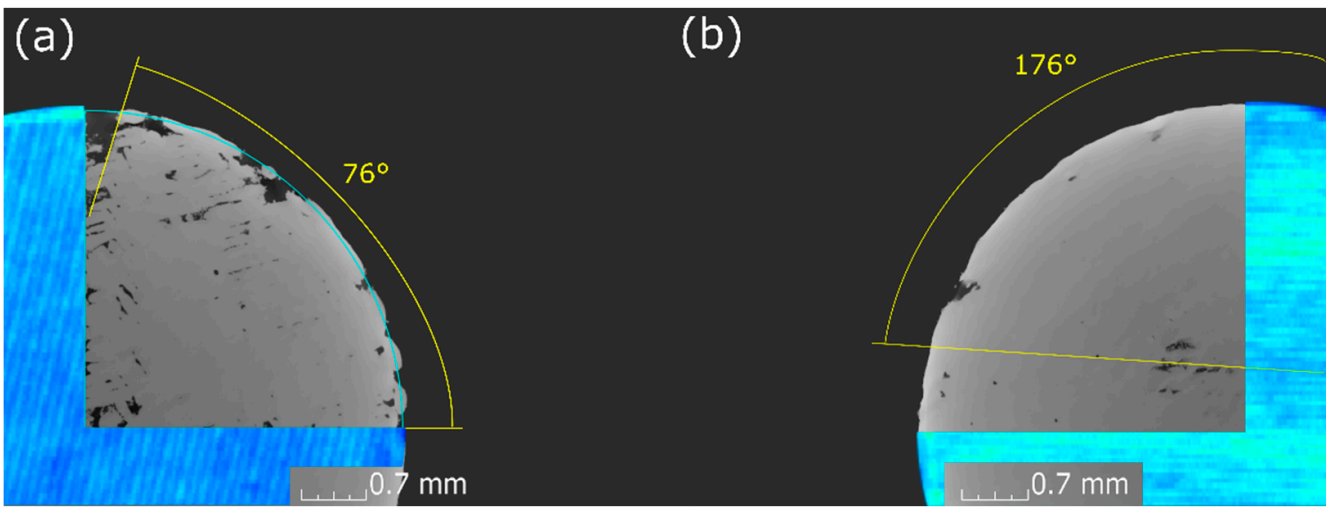

Figure 8. (a) Virtual cut taken at $60 \mu \mathrm{m}$ above the bottom of Q8 combined with an optical tomography image showing the hatch orientation of layer number 200 (last completely exposed layer before Q8). The latter seems to dictate the orientation of the voids more than the layers above. (b) Virtual cut taken at $10 \mu \mathrm{m}$ below the bottom of Q9 combined with an optical tomography image showing the hatch orientation of layer number 220 (last completely exposed layer before Q9). The latter seems to have formed the first voids in the bulk of Q9.

In Figure 9, the top yellow line was drawn from the shape of the cylinder's top surface. This profile was also applied to the internal surfaces of Q9 and Q8. The correspondence between this template and inner surfaces could indicate that this uneven surface was present throughout the whole build process. This indicates that the height difference between the centre and perimeter of the cylinder also existed at lower built heights. The slope explains why the imperfections of layer number 220 were visible in both images of Figure 8. During the build job of the specimen, sky writing was used to ensure a constant scan speed for the whole hatch length. To achieve a constant speed, the laser was turned off at the end of the scan track before repositioning the guiding mirrors. Hence, deceleration and acceleration effects could be avoided. Suddenly turning off the laser resulted in the reported elevated end-sections of scan tracks, followed by a dent as reported by Yeung et al. [35], and corresponds to simulations of the melt flow by Khairallah et al. [31]. According to them, these dents could form pores at the end of scan tracks and might explain the observation of pores at the intersection of the bulk and contour scan in this study. A ring of elevated end-sections of scan tracks has formed throughout the build height of the specimen owing to the $67^{\circ}$ rotation of the applied stripe pattern in the bulk (see Figure 9).

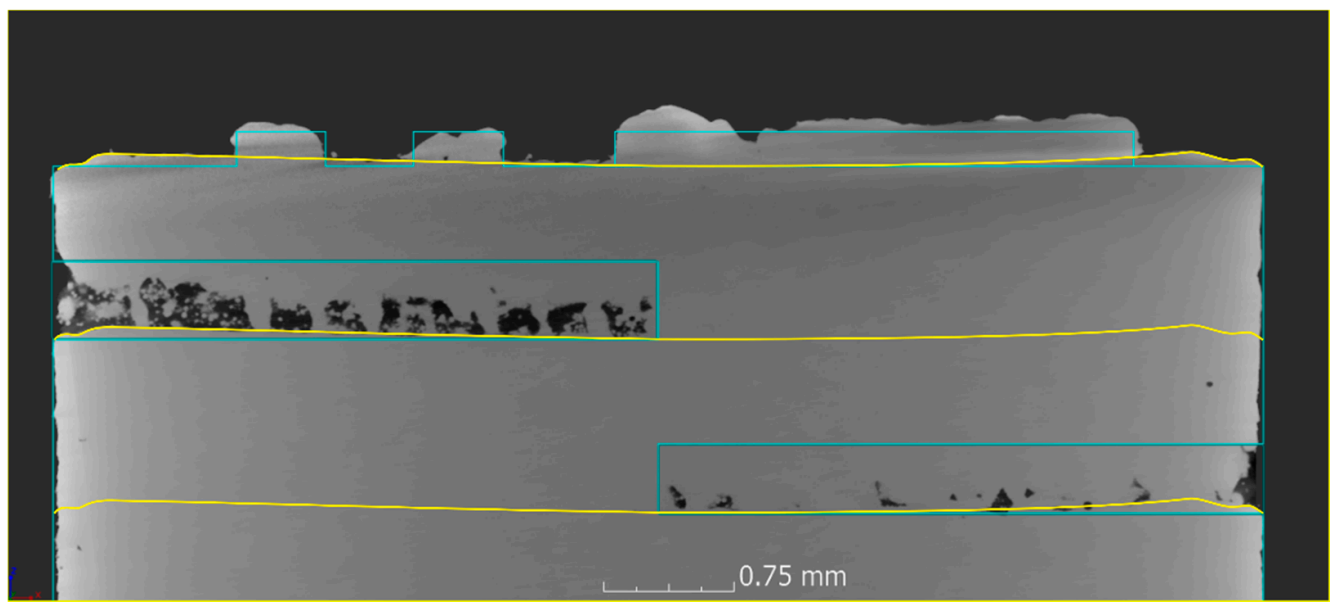

Figure 9. Cross section taken in the middle of the core cylinder showing voids at the bottom edges of Q8 (blue marked area at the bottom of the right side) and Q9 (blue marked area at the left side). The blue lines represent the nominal size taken from the CAD file. Yellow lines emphasize the structure of the internal surface. 


\section{Conclusions}

In this study, we investigated the effect of unmolten powder layers on the defect formation in LPBF AISI 316L. In particular, we determined how many laser-unexposed layers of AISI 316L powder could be molten using a set of basis parameters provided by the LPBF machine's manufacturer. We found that, up to a thickness of $200 \mu \mathrm{m}$ of unexposed powder (i.e., four powder layers), no additional porosity was observed, aside from pores between the bulk and contour scan. Therefore, we conclude that the heat input from the melt pool could sufficiently melt an amount of powder of four layers. We presume that this occurs because of a sufficient melt pool penetration depth, which allows fusion to the underlying solid material, and by being able to allow gas bubbles entrapped between powder particles to escape from the melt.

Further process parameter optimization (not within the scope of this study) might be able to make the process more efficient by, e.g., a slight increase of the scanning velocity. However, for large components, a slightly excessive melting depth can render the build process less prone to process irregularities (e.g., heterogeneities of the powder recoating process).

The present results will enable the interpretation of the signals acquired by in situ monitoring systems, allowing the LPBF users to decide whether or not an irregularly observed signal during the build process will be locked as a defect in the final part.

Our results also suggest that healing among layers occurs only if a scan strategy is applied, where the orientation of the hatches is changed for each subsequent layer. In fact, the porosity observed between the bulk and border scan indicates that healing does not occur if the subsequent layers are applied using the same hatching orientation.

Finally, the present study shows that small pores and surface roughness of solidified material below a thick layer of unmolten material $(>200 \mu \mathrm{m})$ could serve as seeding points for larger voids. The orientation of the first two layers that are fully exposed after a thick layer of unmolten powder shapes the orientation of these voids, created by a lack of fusion.

Author Contributions: Conceptualization, A.U., G.M. and S.J.A.; methodology, A.U., S.J.A. and S.O.; formal analysis, A.U., S.J.A. and S.O.; investigation, A.U., S.J.A. and S.O.; writing-original draft preparation, A.U., G.M., S.J.A., S.O. and C.M.; writing-review and editing, A.U., G.M., S.J.A., S.O., C.M. and G.B.; visualization, A.U. and S.O.; supervision, S.J.A. and G.B.; project administration, S.J.A. and C.M. All authors have read and agreed to the published version of the manuscript.

Funding: This research received no external funding.

Institutional Review Board Statement: Not applicable.

Informed Consent Statement: Not applicable.

Acknowledgments: This work has been funded by the BAM Focus Area Materials project ProMoAM "Process monitoring of Additive Manufacturing". We are thankful for the financial support and the fruitful cooperation with all partners.

Conflicts of Interest: The authors declare no conflict of interest.

\section{References}

1. Frazier, W.E. Metal Additive Manufacturing: A Review. J. Mater. Eng. Perform. 2014, 23, 1917-1928. [CrossRef]

2. Roehling, T.T.; Wu, S.S.Q.; Khairallah, S.A.; Roehling, J.D.; Soezeri, S.S.; Crumb, M.F.; Matthews, M.J. Modulating laser intensity profile ellipticity for microstructural control during metal additive manufacturing. Acta Mater. 2017, 128, 197-206. [CrossRef]

3. Mohr, G.; Altenburg, S.J.; Hilgenberg, K. Effects of inter layer time and build height on resulting properties of 316L stainless steel processed by laser powder bed fusion. Addit. Manuf. 2020, 32, 101080. [CrossRef]

4. Tang, M.; Pistorius, P.C.; Beuth, J.L. Prediction of lack-of-fusion porosity for powder bed fusion. Addit. Manuf. 2017, 14, 39-48. [CrossRef]

5. Metelkova, J.; Kinds, Y.; Kempen, K.; de Formanoir, C.; Witvrouw, A.; Van Hooreweder, B. On the influence of laser defocusing in Selective Laser Melting of 316L. Addit. Manuf. 2018, 23, 161-169. [CrossRef]

6. Mohr, G.; Altenburg, S.J.; Ulbricht, A.; Heinrich, P.; Baum, D.; Maierhofer, C.; Hilgenberg, K. In-Situ Defect Detection in Laser Powder Bed Fusion by Using Thermography and Optical Tomography-Comparison to Computed Tomography. Metals 2020, 10, 103. [CrossRef] 
7. Pradeep, P.I.; Kumar, V.A.; Sriranganath, A.; Singh, S.K.; Sahu, A.; Kumar, T.S.; Narayanan, P.R.; Arumugam, M.; Mohan, M. Characterization and Qualification of LPBF Additively Manufactured AISI-316L Stainless Steel Brackets for Aerospace Application. Trans. Indian Natl. Acad. Eng. 2020, 5, 603-616. [CrossRef]

8. Shange, M.; Yadroitsava, I.; Yadroitsev, S.P.I.; du Plessis, A. Determining the effect of surface roughness and porosity at different inclinations of LPBF parts. In Proceedings of the 20th Annual International RAPDASA Conference, Bloemfontein, South Africa, 6-8 November 2019.

9. Andreau, O.; Pessard, E.; Koutiri, I.; Peyre, P.; Saintier, N. Influence of the position and size of various deterministic defects on the high cycle fatigue resistance of a 316L steel manufactured by laser powder bed fusion. Int. J. Fatigue 2021, 143. [CrossRef]

10. Druzgalski, C.L.; Ashby, A.; Guss, G.; King, W.E.; Roehling, T.T.; Matthews, M.J. Process optimization of complex geometries using feed forward control for laser powder bed fusion additive manufacturing. Addit. Manuf. 2020, 34, 101169. [CrossRef]

11. Repossini, G.; Laguzza, V.; Grasso, M.; Colosimo, B.M. On the use of spatter signature for in-situ monitoring of Laser Powder Bed Fusion. Addit. Manuf. 2017, 16, 35-48. [CrossRef]

12. Forien, J.-B.; Calta, N.P.; DePond, P.J.; Guss, G.M.; Roehling, T.T.; Matthews, M.J. Detecting keyhole pore defects and monitoring process signatures during laser powder bed fusion: A correlation between in situ pyrometry and ex situ X-ray radiography. Addit. Manuf. 2020, 35, 101336. [CrossRef]

13. Scheuschner, N.; Altenburg, S.J.; Gumenyuk, A.; Maierhofer, C. In-situ thermographic monitoring of the laser metal deposition process. In Proceedings of the Sim-AM 2019: II International Conference on Simulation for Additive Manufacturing, Pavia, Italy, 11-13 September 2019; pp. 246-255.

14. Gusarov, A.; Smurov, I. Modeling the interaction of laser radiation with powder bed at selective laser melting. Phys. Procedia 2010, 5, 381-394. [CrossRef]

15. Foroozmehr, A.; Badrossamay, M.; Foroozmehr, E.; Golabi, S.i. Finite Element Simulation of Selective Laser Melting process considering Optical Penetration Depth of laser in powder bed. Mater. Design 2016, 89, 255-263. [CrossRef]

16. Ma, M.; Wang, Z.; Gao, M.; Zeng, X. Layer thickness dependence of performance in high-power selective laser melting of 1Cr18Ni9Ti stainless steel. J. Mater. Process. Technol. 2015, 215, 142-150. [CrossRef]

17. Streek, A.; Regenfuss, P.; Exner, H. Fundamentals of energy conversion and dissipation in powder layers during laser micro sintering. Phys. Procedia 2013, 41, 858-869. [CrossRef]

18. du Plessis, A.; Yadroitsev, I.; Yadroitsava, I.; Le Roux, S.G. X-ray Microcomputed Tomography in Additive Manufacturing: A Review of the Current Technology and Applications. 3D Print. Addit. Manuf. 2018, 5, 227-247. [CrossRef]

19. Marattukalam, J.J.; Karlsson, D.; Pacheco, V.; Beran, P.; Wiklund, U.; Jansson, U.; Hjörvarsson, B.; Sahlberg, M. The effect of laser scanning strategies on texture, mechanical properties, and site-specific grain orientation in selective laser melted 316L SS. Mater. Design 2020, 193, 108852. [CrossRef]

20. Gobert, C.; Reutzel, E.W.; Petrich, J.; Nassar, A.R.; Phoha, S. Application of supervised machine learning for defect detection during metallic powder bed fusion additive manufacturing using high resolution imaging. Addit. Manuf. 2018, 21, 517-528. [CrossRef]

21. Bamberg, J.; Zenzinger, G.; Ladewig, A. In-process control of selective laser melting by quantitative optical tomography. In Proceedings of the 19th World Conference on Non-Destructive Testing, Munich, Germany, 3-17 June 2016.

22. Oesch, T.; Weise, F.; Meinel, D.; Gollwitzer, C. Quantitative In-situ Analysis of Water Transport in Concrete Completed Using X-ray Computed Tomography. Transp. Porous Media 2019, 127, 371-389. [CrossRef]

23. Buades, A.; Coll, B.; Morel, J.-M. Non-Local Means Denoising. Image Process. Line 2011, 1. [CrossRef]

24. Darbon, J.; Cunha, A.; Chan, T.F.; Osher, S.; Jensen, G.J. Fast nonlocal filtering applied to electron cryomicroscopy. In Proceedings of the 2008 5th IEEE International Symposium on Biomedical Imaging: From Nano to Macro, Paris, France, 14-17 May 2008; pp. 1331-1334.

25. Schindelin, J.; Arganda-Carreras, I.; Frise, E.; Kaynig, V.; Longair, M.; Pietzsch, T.; Preibisch, S.; Rueden, C.; Saalfeld, S.; Schmid, B.; et al. Fiji: An open-source platform for biological-image analysis. Nat. Methods 2012, 9, 676-682. [CrossRef] [PubMed]

26. Ertay, D.S.; Ma, H.; Vlasea, M. Correlative Beam Path and Pore Defect Space Analysis for Modulated LPBF Process. In Proceedings of the 2018 Annual International Solid Freeform Fabrication (SFF) Symposium-An Additive Manufacturing (AM) Conference, Austin, TX, USA, 13-15 August 2018.

27. Denlinger, E.R.; Jagdale, V.; Srinivasan, G.V.; El-Wardany, T.; Michaleris, P. Thermal modeling of Inconel 718 processed with powder bed fusion and experimental validation using in situ measurements. Addit. Manuf. 2016, 11, 7-15. [CrossRef]

28. Li, E.L.; Wang, L.; Yu, A.B.; Zhou, Z.Y. A three-phase model for simulation of heat transfer and melt pool behaviour in laser powder bed fusion process. Powder Technol. 2021, 381, 298-312. [CrossRef]

29. Qiu, C.; Panwisawas, C.; Ward, M.; Basoalto, H.C.; Brooks, J.W.; Attallah, M.M. On the role of melt flow into the surface structure and porosity development during selective laser melting. Acta Mater. 2015, 96, 72-79. [CrossRef]

30. Clark, S.J.; Leung, C.L.A.; Chen, Y.; Sinclair, L.; Marussi, S.; Lee, P.D. Capturing Marangoni flow via synchrotron imaging of selective laser melting. IOP Conf. Ser. Mater. Sci. Eng. 2020, 861. [CrossRef]

31. Khairallah, S.A.; Anderson, A.T.; Rubenchik, A.; King, W.E. Laser powder-bed fusion additive manufacturing: Physics of complex melt flow and formation mechanisms of pores, spatter, and denudation zones. Acta Mater. 2016, 108, 36-45. [CrossRef]

32. Biffi, C.A.; Fiocchi, J.; Valenza, F.; Bassani, P.; Tuissi, A. Selective Laser Melting of NiTi Shape Memory Alloy: Processability, Microstructure, and Superelasticity. Shape Mem. Superelasticity 2020, 6, 342-353. [CrossRef] 
33. Fiocchi, J.; Biffi, C.A.; Tuissi, A. Selective laser melting of high-strength primary AlSi9Cu3 alloy: Processability, microstructure, and mechanical properties. Mater. Design 2020, 191, 108581. [CrossRef]

34. Biffi, C.A.; Bassani, P.; Fiocchi, J.; Albu, M.; Tuissi, A. Selective laser melting of AlCu-TiB2 alloy using pulsed wave laser emission mode: Processability, microstructure and mechanical properties. Mater. Design 2021, 204. [CrossRef]

35. Yeung, H.; Lane, B.M.; Donmez, M.A.; Fox, J.C.; Neira, J. Implementation of Advanced Laser Control Strategies for Powder Bed Fusion Systems. Procedia Manuf. 2018, 26, 871-879. [CrossRef] 